УДК 615.012;004.942

КОМПЬЮТЕРНОЕ МОДЕЛИРОВАНИЕ КАК ОДИН ИЗ СОВРЕМЕННЫХ МЕТОДОВ ПРОГНОЗИРОВАНИЯ В ФАРМАЦЕВТИЧЕСКОЙ ТЕХНОЛОГИИ

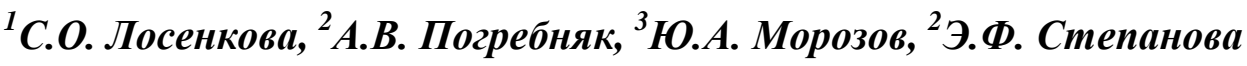

${ }^{1}$ Смоленская государственная медицинская академия, г. Смоленск

${ }^{2}$ Пятигорский медико-фармацевтический институт - филиал ГБОУ ВПО ВолгГМУ

Минздрава России, г. Пятигорск

${ }^{3}$ Северо-Осетинский государственный университет им. К.Л. Хетагурова, г. Владикавказ

E-mail: losenkova-so@mail.ru

В работе проведены исследования, посвященные прогнозированию совместимости вспомогательных и лекарственных веществ с помощью метода компьютерного моделирования с целью их использования в разработке составов и технологии трансдермальных терапевтических систем.

Ключевые слова: компьютерный дизайн, молекулярные дескрипторы, вспомогательные вещества, этилметилгидроксипиридина сукцинат, натрия поли(дигидроксифенилен)тиосульфонат.

\title{
COMPUTER MODELING AS ONE OF CONTEMPORARY METHODS OF FORECASTING IN PHARMACEUTICAL TECHNOLOGY
}

\author{
${ }^{1}$ S.O. Losenkova, ${ }^{2}$ A.V. Pogrebnyak, ${ }^{3}$ Yu.A. Morozov, ${ }^{2}$ E.F. Stepanova \\ ${ }^{1}$ Smolensk State Medical Academy, Smolensk \\ ${ }^{2}$ Pyatigorsk Medical and Pharmaceutical Institute - a branch of Volgograd State Medical \\ University, Pyatigorsk \\ ${ }^{3}$ North Ossetian State University after K.L. Khetagurov, Vladikavkaz \\ E-mail:losenkova-so@mail.ru
}

The work presents researches devoted to the forecasting of compatibility of additive and drug substances with a method of computer modeling for its use in composition elaboration and technology of transdermal therapeutic systems.

Keywords: computer design, molecular descriptor, additive substances, ethylmethylhydroxypyridine succinate, sodium poly(dihydroxyfenilene)thiosulphonate.

Хранение лекарственного препарата, особенно длительное, неизбежно сопровождается процессами деструкции его компонентов под действием внешних факторов (химических и физических), а также в результате внутренних процессов аутоокисления и аутовосстановления. Первую, внешнюю, составляющую процесса деструкции в фармацевтической технологии обычно устраняют применением соответствующей упаковки (темное стекло, металлизированные пленки, вакуумирование) и решение данной проблемы в настоящее время не представляет какой-либо трудности.

Напротив, внутренние факторы, влияющие на стабильность, а, следовательно, на безопасность лекарственного средства (ЛС), как правило, изучаются лишь эмпирически, по данным анализа продуктов разложения при естественном или искусственном (ускоренном) старении. При этом идет лишь констатация фактов, без анализа возможных причин [1]. 
Поэтому на каждом этапе создания новой лекарственной формы (ЛФ) необходимо проводить качественную и количественную оценку взаимного влияния всех ее составляющих компонентов. Это позволяет не только правильно оценить стабильность ЛФ, но спланировать высвобождение активных компонентов ЛФ в желаемой последовательности.

В настоящее время для предсказания физиологической активности, совместимости ЛВ и вспомогательных веществ (BВ), установления зависимости между структурой и свойствами веществ применяется компьютерное и математическое моделирование.

Методологией QSAR является исследование количественной взаимосвязи между структурой и активностью, при использовании которой структура химического соединения выражается определенными дескрипторами (параметрами): молекулярный вес, число атомов определенного типа, связей или групп, молекулярный объем, частичные заряды на атомах. Для предсказания физиологической активности в QSAR используют дескрипторы, рассчитанные на основе стерических, топологических особенностей структуры, электронных эффектов, липофильности.

Дескрипторы электронных эффектов описывают ионизацию или полярность соединений, дескрипторы липофильности позволяют произвести оценку способности растворяться в жирах, а значит, способность ЛВ преодолевать клеточные мембраны и биологические барьеры. Использование модели QSAR (математического уравнения) за рубежом при создании новых соединений с заданными свойствами позволяет значительно сократить время и ресурсы, а также осуществлять более целенаправленный синтез соединений [2].

Компьютерное моделирование ЛП или компьютерный дизайн лекарств (CADD) представляет собой совокупность вычислительных методов (включая QSAR) и программ, используемых для направленного молекулярного дизайна лекарств. Вычислительный дизайн полностью не возможен, так как многие свойства потенциальных ЛП можно определить исключительно экспериментальным путем (вычислительные оценки носят лишь качественный характер).

Компьютерный дизайн CADD рассматривается как частное направление CAMD компьютерного молекулярного дизайна.

Методология QSAR используется и в отечественных компьютерных программах. Работа программы компьютерного скрининга PASS основана на анализе зависимости «структура-активность» для веществ из постоянно пополняющейся выборки, содержащей более 45000 разнообразных БАВ. Химическая структура представлена в PASS в виде оригинальных МNA-дескрипторов, описывающих разнообразные зависимости «структура-свойство» с достаточной точностью. Точность в 85\% достаточна для практического применения системы PASS с целью прогноза спектра биологической активности новых веществ [2].

Реализована возможность прогноза спектра биологической активности веществ через Интернет. Используя стандартные браузеры Google Chrome или Internet Explorer, можно направить на прогноз структурную формулу вещества (в виде mol-файла) и автоматически получить на дисплее прогноз видов биологической активности наиболее вероятных для изучаемого химического соединения.

Программа Solubility SC разработана на кафедре кибернетики химикотехнологических процессов Российского химико-технологического университета им. Д.И. Менделеева. Во многих областях химии и химической технологии в настоящее время проводятся интенсивные исследования по применению сверхкритических флюидов в качестве растворителей в процессах экстракции, сепарации, адсорбции. Программа Solubility SC позволяет спрогнозировать растворимость некоторого вещества при сверхкритических условиях. База данных программы содержит информацию по 
растворимости около 300 соединений в сверхкритическом диоксиде углерода и других растворителях [3].

Для прогнозирования растворимости в программе используются полуэмпирические модели, основанные на теории сольватации, а также методология QSPR. C помощью данной программы возможен просмотр структурной формулы вещества, его трехмерного строения, расчетных данных по растворимости, плотности сверхкритических растворителей, более 100 химических дескрипторов, а также поиск корреляции между ними и растворимостью соединений.

Клеточные автоматы, аналогично методологии QSAR, активно используются как интуитивно понятийный инструмент моделирования физико-химических явлений. Это метод дискретно-динамического моделирования с возможностью использования параллельных вычислений. Объект представляется моделью, образованной множеством равновеликих клеток. Каждой клетке может быть приписано некоторое значение свойства системы (концентрация, температура, давление и др.), которые периодически могут изменяться. Клеточно-автоматная модель используется при изучении высвобождения ЛВ из микросфер, таблеток, позволяет описывать различные сценарии высвобождения и может рассматриваться как эффективный инструмент предсказания кинетических кривых [4].

Организацией-разработчиком программы DockSearch является Институт биомедицинской химии им. В.Н. Ореховича РАМН. Молекулярная стыковка или молекулярный докинг - это метод молекулярного моделирования, который позволяет предсказать наиболее выгодную для образования устойчивого комплекса ориентацию и положение одной молекулы по отношению к другой. Знания о предсказанной ориентации могут быть использованы для предсказания прочности комплекса или сродства связей между двумя молекулами. Комплексы таких биологически значимых молекул как белки, нуклеиновые кислоты, углеводы и липиды, играют ключевую роль в передаче химического сигнала. Стыковка часто используется для предсказания аффинности и активности небольшой молекулы лекарства по отношению к белку-мишени [5].

Направленное конструирование новых ЛП или драгдизайн имеет прямое отношение к нанотехнологиям, поскольку взаимодействующие объекты (лекарство и мишень) являются молекулярными объектами. На сегодняшний день конструирование лекарств - это синергизм геномики, протеомики, химии, медицины и информатики.

На первом этапе теоретического исследования были вычислены основные молекулярные дескрипторы фосфолипида и всех предполагаемых компонентов трансдермальной терапевтической системы (ТДТС) пластырного типа.

Второй этап предполагал расчет динамики проникновения этилметилгидроксипиридина сукцината через липидный бислой и выбор оптимальной композиции вспомогательных веществ с учетом их возможного взаимного влияния. Для получения четкого представления о способах преодоления БАВ барьеров живого организма (кожного покрова), необходимо давать качественное и количественное описание липидного бислоя, являющегося основой биологических мембран.

В работе Морозова Ю.А. (2008г.) представлен фрагмент бислоя, являющийся основой для теоретической модели трансдермального проникновения ЛВ. Структурную основу мембраны составляет липидный матрикс, организованный в форме бислоя. Элементарными структурами, формирующими бислой, а значит и мембрану, являются молекулы фосфолипида и холестерола.

Оптимизацию геометрии молекул лекарственных веществ производили при помощи интеграционной процедуры поиска локального минимума на поверхности потенциальной энергии (ППЭ). Локализацию минимума на ППЭ осуществляли двумя основными расчетными схемами: молекулярной механики (предварительный метод) и методом молекулярных орбиталей (МО) [6]. 
Полученная в результате оптимизации методом МО - АМ1 геометрия использована далее для расчета физико-химических дескрипторов (табл. 1-4).

Для первичной оптимизации геометрии использовано силовое поле ММР2. В силу своей экономичности с точки зрения затрат машинного времени данный метод использован в основном для первичного анализа конформационной заселенности. MMP2.

В качестве стартовой для методов МО взята геометрия, полученная методом

Полученная в результате оптимизации МО методом РМ3 геометрия использована далее для расчета физико-химических дескрипторов другими полуэмпирическими методами.

Главными физико-химическими дескрипторами, определяющими взаимные реакционную способность и степень адсорбции молекул, являются:

- потенциал ионизации с учетом гидратации (РМ3);

- сродство к электрону с учетом гидратации (РМ3);

- $\quad \alpha$-поляризуемость (РМ3);

- дипольный момент в газовой фазе (РМ3);

- коэффициент распределения в системе «октанол-вода» $\log \mathrm{P}$ (аддитивный метод расчета).

С целью прогнозирования совместимости лекарственных и вспомогательных веществ, входящих в состав разрабатываемых ТДТС пластырного типа, проведены квантовохимические расчеты структурных элементов ЛВ из группы антиоксидантов и антигипоксантов, результаты которых представлены в таблице 1.

Таблица 1 - Результаты расчета основных физико-химических дескрипторов молекул этилметилгидроксипиридина сукцината и натрия поли(дигидроксифенилен) тиосульфоната

\begin{tabular}{|c|c|c|c|c|c|c|}
\hline \multirow{2}{*}{$\begin{array}{l}\text { Лекарственные } \\
\text { вещества }\end{array}$} & \multicolumn{6}{|c|}{ Дескрипторы } \\
\hline & $\begin{array}{l}\text { Поляри- } \\
\text { зуемость, } \\
\text { A3 }\end{array}$ & $\begin{array}{l}\text { Коэффициент } \\
\text { распределения, } \\
\log \mathrm{P}\end{array}$ & $\begin{array}{l}\text { Энергия } \\
\text { гидратации, } \\
\text { ккал/моль }\end{array}$ & $\begin{array}{l}\mathrm{HCMO}, \\
\text { эB }\end{array}$ & $\begin{array}{l}\text { B3MO, } \\
\text { эB }\end{array}$ & $\begin{array}{l}\text { Дипольный } \\
\text { момент, Д }\end{array}$ \\
\hline $\begin{array}{l}\text { Этилметил- } \\
\text { гидроксипиридина } \\
\text { сукцинат } \\
\text { (мексидол) }\end{array}$ & 15,87 & 0,55 & $-4,89$ & $+0,007$ & $-9,153$ & 2,49 \\
\hline $\begin{array}{l}\text { Натрия } \\
\text { поли(дигидрокси- } \\
\text { фенилен)- } \\
\text { тиосульфонат } \\
\text { (гипоксен) }\end{array}$ & 16,48 & $-1,19$ & $-24,36$ & $-2,414$ & $-9,115$ & 3,78 \\
\hline
\end{tabular}

Химические формулы и результаты квантово-химических расчетов структурных элементов вспомогательных веществ, используемых в технологии ТДТС, приведены в таблице 2. 
Таблица 2 - Результаты квантово-химических расчетов структурных элементов вспомогательных веществ

\begin{tabular}{|c|c|c|c|c|c|c|}
\hline $\begin{array}{l}\text { Вспомогательные вещества } \\
\text { и их структурные формулы }\end{array}$ & 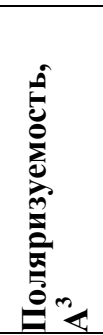 & 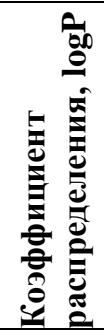 & 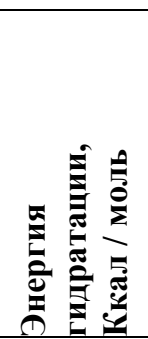 & $\sum_{0}^{0}$ & $\sum_{m}^{0}$ & 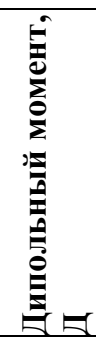 \\
\hline Полиэтиленоксид & 18,64 & $-1,2$ & $-16,08$ & $+2,03$ & $-10,61$ & 1,68 \\
\hline Інилпирро. & 37,63 & $-0,55$ & 1,59 & $+0,98$ & $-9,37$ & 6,51 \\
\hline гилсульфоксид & 5,01 & $-0,68$ & $-1,36$ & $+0,26$ & $-9,35$ & 4,49 \\
\hline Твин-80 & 63,15 & 2,43 & $-18,40$ & $+1,02$ & $-9,82$ & 5,28 \\
\hline Пропиленгликоль-1,2 & 7,55 & $-0,30$ & $-10,81$ & $+2,97$ & $-11,02$ & 2,11 \\
\hline
\end{tabular}

Примечание: теплоту гидратации рассчитывали по уравнению: $\mathrm{H}_{\text {hydr }}=\mathrm{H}_{\mathrm{aq}}-\mathrm{H}_{\mathrm{vac}}$, где $\mathrm{H}_{\mathrm{hydr}}-$ энергия гидратации молекулы, ккал/моль; $\mathrm{H}_{\text {aq }}$ - теплота образования молекулы с учетом эффекта гидратации, ккал/моль; $\mathrm{H}_{\text {vac }}$ - теплота образования без учета гидратации, ккал/моль.

Величина десятичного логарифма коэффициента распределения в модельной системе «октанол-вода» позволяет прогнозировать проницаемость БАВ через биомембраны [7].

Для последующего разделения ЛВ и ВВ на кластеры исходные данные всех компонентов были сгруппированы в виде таблицы 3.

Анализ литературных данных позволил дополнительно определить величину десятичного логарифма коэффициента распределения в модельной системе «октанолвода» и значение энергии гидратации спирта этилового $(+0,08$ и $-5,81)$, фосфолипида $(+14,24 ;-1,67)$ и холестерола $(+7,17 ;-0,08)$, являющихся структурными элементами биологической мембраны [7]. 
Таблица 3 - Исходные данные для кластерного анализа

\begin{tabular}{|l|l|l|l|l|l|l|}
\hline Mexidol & Hypoxen & PEG-400 & PVP & DMSO & Tween80 & PG-1,2 \\
\hline 15,87 & 16,48 & 18,64 & 37,63 & 5,01 & 63,15 & 7,55 \\
\hline 0,55 & $-1,19$ & $-1,20$ & $-0,55$ & $-0,68$ & 2,43 & $-0,30$ \\
\hline$-4,89$ & $-24,36$ & $-16,08$ & 1,59 & $-1,36$ & $-18,40$ & $-10,81$ \\
\hline 0,01 & $-2,41$ & 2,03 & 0,98 & 0,26 & 1,02 & $+2,97$ \\
\hline$-9,15$ & $-9,12$ & $-10,61$ & $-9,37$ & $-9,35$ & $-9,82$ & $-11,02$ \\
\hline 2,49 & 3,78 & 1,68 & 6,51 & 4,49 & 5,28 & 2,11 \\
\hline
\end{tabular}

Далее найденные теоретически дескрипторы в форме таблицы 3 перенесены в статистическую программу, где с ними произведена стандартная процедура разделения на кластеры методом k-среднего. Результаты разделения представлены в таблице 4.

Таблица 4 - Результаты разделения лекарственных и вспомогательных веществ на кластеры

\begin{tabular}{|l|c|c|c|}
\hline $\begin{array}{l}\text { Лекарственные и } \\
\text { вспомогательные } \\
\text { вещества }\end{array}$ & VARIABLE & CLUSTER & DISTANCE \\
\hline Mexidol & 1 & 3 & 2,20 \\
\hline Hypoxen & 2 & 1 & 2,04 \\
\hline PEG-400 & 3 & 1 & 2,04 \\
\hline PVP & 5 & 3 & 7,56 \\
\hline DMSO & 6 & 3 & 5,92 \\
\hline Tween-80 & 7 & 2 & 0,00 \\
\hline PG-1,2 & 5 & 6,01 \\
\hline
\end{tabular}

Анализ результатов проведения кластерного анализа показывает, что в одинаковые группы (кластеры) веществ со сходными физико-химическими дескрипторами попадают ЛВ и некоторые ВВ (полимеры).

Таким образом, в кластер №1 попадает натрия поли(дигидроксифенилен)тиосульфонат (гипоксен) и полиэтиленоксид-400, а в кластер №3 - этилметилгидроксипиридина сукцинат (мексидол), поливинилпирролидон, пропиленгликоль-1,2 и диметилсульфоксид.

Твин-80 оказался единственным представителем кластера №2. Спирт этиловый изза высокого сродства к воде и общей химической инертности значимо не влияет на свойства ЛФ.

Далее была проанализирована генетическая близость рассчитанных соединений и сделаны выводы об их физико-химическом сродстве. Построен график парной зависимости коэффициента распределения «октанол-вода» и теплот гидратации исследуемых компонентов предполагаемой ТДТС пластырного типа. Точки озаглавлены первыми буквами названий молекул. Непрерывная красная кривая между точками линия тренда, позволяющая графически отображать тенденции данных и прогнозировать их дальнейшие изменения (рис. 1). Подобный анализ называется также регрессионным анализом. Используя регрессионный анализ, можно продлить линию тренда в диаграмме за пределы реальных данных для предсказания будущих значений. 


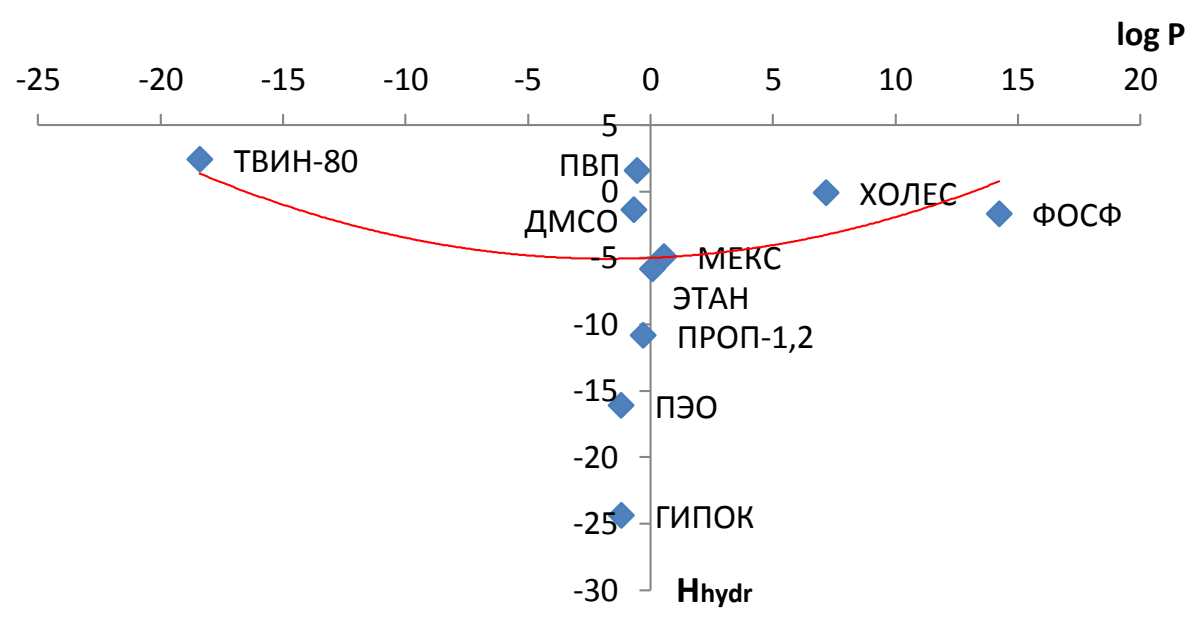

Рисунок 1 - График зависимости Hhydr-IgP и линия тренда

Максимальное сходство физико-химических дескрипторов этилметилгидроксипиридина сукцината (мексидола) наблюдается с дескрипторами ПВП, ДМСО (рис. 1). Близость физико-химических дескрипторов, с одной стороны, обеспечивает взаимную химическую инерцию (близость электронодонорной и электронакцепторной способности) и достаточное адсорбционное взаимодействие - с другой (близость коэффициентов распределения «октанол-вода» и энергий гидратации). Предположительно, медленнее мексидол должен высвобождаться именно из ПВП за счет адсорбционного взаимодействия полимера и ЛВ. В свою очередь, ПЭО-400, твин-80 отдаленно расположены от мексидола и могут обеспечить его лучшее высвобождение. Следовательно, совместное применение ПВП и ПЭО-400, твина-80 будет способствовать более длительному и равномерному высвобождению этилметилгидроксипиридина сукцината и усилению проницаемости кожи.

Наряду с пластификатором ПЭО-400, целесообразно использовать также и пропиленгликоль-1,2. Исходя из рис. 1, пропиленгликоль-1,2 обладает большим сходством физико-химических дескрипторов с таковыми у мексидола, чем полиэтиленоксид - 400, однако по пенетрирующим свойствам превосходит его.

Таким образом, анализ строения полимеров и БАВ позволяют сделать вывод о том, что в состав ЛФ с поли(дигидроксифенилен)тиосульфонатом натрия (гипоксеном) предположительно нужно включать ПЭГ-400, который может обеспечить взаимную химическую инерцию с ЛВ. Твин-80 расположен отдаленно от гипоксена (рис. 1), поэтому может обеспечить его лучшее высвобождение из ЛФ, но степень химической инерции между ЛВ и ВВ уменьшается. Включение в состав тЛФ с этилметилгидроксипиридина сукцинатом (мексидолом) ПВП, ПЭО-400 и пропиленгликоля-1,2 предположительно может обеспечить длительный чрескожный транспорт ЛВ.

Предложенный способ определения сродства молекул БАВ и структурных элементов ЛФ позволяет на ранних этапах планирования способа транспорта данного вещества к тканям определять какие именно материалы пригодны для адсорбции (удержания) того или иного соединения, что позволяет значительно сузить объем соответствующего эксперимента, а также увеличить срок хранения.

Кроме того, с помощью компьютерных программ возможно прогнозирование спектра фармакологической активности ЛВ. Для исследования этилметилгидроксипиридина сукцината были использованы два отечественных компьютерных алгоритма - Matrix* и PASS* [6]. 
Исходным объектом для прогнозирования явилась структурная формула этилметилгидроксипиридина (без учета сукцината) для программы PASS, и пространственная модель молекулы этилметилгидроксипиридина (эмоксипина) для программы Matrix. В обоих случаях наличие в составе препарата янтарной кислоты считали влияющим только на фармакокинетические свойства и не определяющим основной спектр биологического действия.

Известными для мексидола основными видами биологической активности являются антиоксидантная, антигипоксантная активность, антикоагулирующая, антимутагенная, мембраностабилизирующая, радиопротекторная, кардиопротекторная активность.

Результаты работы алгоритма Matrix указывают на то, что основание этилметилгидроксипиридина также может проявлять и другие виды биологической активности, расположенные в порядке убывания вероятности: блокирование Н1гистаминовых рецепторов (по типу действия геминейрина), блокирование аденозиновых рецепторов и угнетение фосфодиэстеразы (по типу действия кофеина), болеутоляющее и противовоспалительное действие (по типу действия цитраля), влияние на дофаминовые рецепторы с улучшением гемодинамики, ингибирование холинестеразы (по типу амиридина), помощь при отравлении ФОС (по типу реактиваторов холинестеразы), антиаритмическое действие, коррекция постинфарктных состояний (по типу мексилетина), возбуждение сосудо-двигательного и дыхательного центра (по типу кордиамина), стимулирование ЦНС, анорексигенный эффект (по типу фенамина), противоопухолевое действие (по типу эмбихина), общие эффекты витамина $\mathrm{B}_{6}$ и гистидина (незаменимой аминокислоты).

Результаты работы алгоритма PASS указывают на то, что этилметилгидроксипиридин может проявлять следующие виды биологической активности в порядке убывания вероятности: антисеборейный эффект, противоаритмический, противоишемический и противоанемический эффекты. Результаты алгоритма PASS указывают на то, что метаболизм препарата, вероятно, будет проходить с участием CYP2D16.

В результате проведенного теоретического обоснования выбора ВВ были сконструированы и изучены 6 модельных образцов с этилметилгидроксипиридина сукцинатом и 5 модельных образцов с натрия поли(дигидроксифенилен)тиосульфонатом, представляющие собой гидрофильные матрицы и включающие ЛВ, пластификаторы, пролонгаторы, растворители [8].

\section{Выводы}

1. Компьютерное моделирование (компьютерный дизайн) является современным методом в фармацевтической технологии, позволяющим спрогнозировать не только совместимость лекарственных и вспомогательных веществ, но и спектр фармакологической активности субстанций ЛВ.

2. Использование программ компьютерного моделирования в фармацевтической технологии позволит упростить процесс разработки и создания ЛП.

\section{Библиографический список}

1. Башкирова, С.Н. Теоретическая оценка взаимного влияния компонентов на общую стабильность препарата / С.Н. Башкирова, А.В. Погребняк, Э.Ф. Степанова // Вестник новых медицинских технологий. - 2006. - Т. XIII, №1.- С.102-104.

2. Инновационные технологии и оборудование фармацевтического производства / Н.В. Меньшутина, Ю.В. Мишина, С.В. Алвес и др. // под ред. проф. Н.В. Меньшутиной. М.: БИНОМ, 2013. - Т. 2 - 480 с. 
3. Cellular automata model for drug release from binary matrix and reservoir polymeric devices / T.J. Laaksonen, H.M. Laaksonen, J.T. Hirvonenet et al. // Biomaterials. - 2009. Vol.30. - P.1978-1987.

4. Электронное обучение по химико-технологическим и фармацевтическим специальностям / Ю.В. Мишина, Н.В. Меньшутина, Е.В. Гусева и др. - Калуга: Изд-во научной литературы Н.Ф. Бочкаревой, 2007. - 104c.

5. О практическом использовании системы прогнозирования биологической активности «Matrix» / А.В. Погребняк, Л.В. Погребняк, А.А. Глушко и др. // Разработка, исследование и маркетинг новой фармацевтической продукции: сб. науч. тр. межрегион. конф. по фармации и фармакологии. - Пятигорск, 2003. - Вып. 58. - С. 360.

6. Морозов Ю.А. Разработка состава и фармакотехнологическое исследование трансдермальной лекарственной формы гиполипидемического действия с диизопропиламмония дихлорацетатом: Автореф. дис. канд. фармац. наук. - Пятигорск, 2008. -27 c.

7. Лосенкова С.О. Теоретическое и экспериментальное обоснование создания трансдермальных лекарственных форм с антиоксидантами и антигипоксантами: Автореф. дис. докт. фармац. наук - М., 2013. - 41 с.

$$
* * *
$$

Лосенкова Светлана Олеговна - доктор фармацевтических наук, доцент, заведуюший кафедрой фармаџевтической технологии ГБОУ ВПО «Смоленская государственная медицинская академия» Минздрава России. Область научньх интересов: разработка и фармакотехнологические исследования трансдермальных лекарственных форм: ТДТС, мазей, гелей, разработка технологии сиропов. E-mail: losenkova-so@mail.ru.

Погребняк Андрей Владимирович - доктор химических наук, кандидат фармачевтических наук, заведующий отделом информационных технологий, заведующий кафедрой физической и коллоидной химии Пятигорского медико-фармацевтического института - филиала ГБОУ ВПО ВолгГМУ Минздрава России. Область научных интересов: квантовая химия, молекулярное моделирование, прогнозирование биологической активности химических соединений. E-mail: a.v.pogrebnyak@pmedpharm.ru.

Морозов Юрий Алексеевич - кандидат фармаџевтических наук, доиент кафедры технологии лекарственных форм и организаџии фармачевтического дела ФГБОУ ВПО «Северо-Осетинский государственный университет имени К.Л. Хетагурова». Область научных интересов: технология приготовления лекарств, трансдермальные лекарственные формы. E-mail: moroz52@yandex.ru.

Степанова Элеонора Федоровна - доктор фармачевтических наук, профессор, профессор кафедры технологии лекарств Пятигорского медико-фармацевтического института - филиала ГБОУ ВПО ВолгГМУ Минздрава России. Область научных интересов: разработка составов и фармакотехнологические исследования мягких, жидких, твердых ЛФ. E-mail: efstepanova@yandex.ru. 